\title{
Optimal Location of Battery Swap Stations for Electric Vehicles
}

\author{
Ubicación Óptima de Estaciones de Intercambio de Baterías para Vehículos \\ Eléctricos
}

\author{
F. A. Osorio-Cruz iD; R. A. Hincapié-Isaza iD; R. A. Gallego-Rendón iD
}

\begin{abstract}
Nowadays, the use of electric vehicles is increasing, due to the positive impact on climate change. This situation requires new methodologies that allow its inclusion in electricity distribution networks. For this reason, a methodology that allows to determine the location and optimal sizing of battery swap stations (BSS) for electric vehicles in distribution networks is proposed, which objective is to minimize investment costs and technical losses of the network. The set of constraints is associated with technical and operational characteristics of the system. To solve the mathematical model, an evolutionary algorithm is used. To verify the efficiency of the methodology, a Colombian distribution system is used, where the locations of BSS allow reducing the investment and operation costs in the distribution systems.
\end{abstract}

Index Terms-Charging stations, power systems, electric vehicles, genetic algorithms.

Resumen-Hoy en día el uso de vehículos eléctricos está aumentando, debido a su impacto positivo en el cambio climático. Esta situación requiere nuevas metodologías que permitan su inclusión en las redes de distribución eléctrica. Por este motivo, se propone una metodología que permite determinar la ubicación y el tamaño óptimo de las estaciones de intercambio de batería (BSS) para vehículos eléctricos en redes de distribución, cuyo objetivo es minimizar los costos de inversión y las pérdidas técnicas de la red. El conjunto de restricciones está asociado a las características técnicas y operativas del sistema. Para resolver el modelo matemático se utiliza un algoritmo evolutivo. Para verificar la eficiencia de la metodología, se utiliza un sistema de distribución colombiano, donde las ubicaciones de BSS permiten reducir los costos de inversión y operación en los sistemas de distribución.

This manuscript was sent on April 25, 2019 and accepted on September 23 , 2019. This work was supported by the Universidad Tecnológica de Pereira, Colombia, under Grant 6-19-8.

F. A. Osorio-Cruz is with the Department of Electrical Engineering at the Universidad Tecnológica de Pereira, Carrera 27 \#10-02 Barrio Álamos, Risaralda-Colombia (fabioandresosorio@utp.edu.co).

R. A. Hincapié-Isaza is Professor in the Department of Electrical Engineering at the Universidad Tecnológica de Pereira, Carrera 27 \#10-02 Barrio Álamos, Risaralda - Colombia (ricardohincapie@utp.edu.co).

R. A. Gallego-Rendón is Professor in the Department of Electrical Engineering at the Universidad Tecnológica de Pereira, Carrera 27 \#10-02 Barrio Álamos, Risaralda - Colombia (ragr@utp.edu.co).
Palabras claves - Estaciones de recarga, sistemas de potencia, vehículos eléctricos, algoritmos genéticos.

\section{INTRODUCTION}

$T$ HE latent increase in environmental pollution of the planet has grown since the mid-twentieth century in an accelerated manner, for which the world has seen the need to take strong actions to reduce the change of this problem. Thus, agreements such as the Kyoto Protocol and government policies have been launched as a primary objective to reduce the said emissions. To minimize the problem, various strategies have been proposed, among which the possibility of integrating electrical vehicles (EV) into the transport system stands out.

Because of this, in recent years there has been a growing interest due to the rising price of oil, government incentives that facilitate the acquisition of these vehicles and the progress of technological developments that allow the EV to be competitive in the vehicular market [1].

According to Navigant Research, the average price of fuel will probably continue to rise during this decade, boosting the $\mathrm{EV}$ demand. This is corroborated by the sales of electric vehicles in the global car market. Some studies have estimated that throughout the year 2030 the proportion of EV would reach $64 \%$ of the total of light vehicles. Regarding Colombia, a large increase in the use of EV is expected for the next years. Within this context, the International Energy Agency estimates that the transport sector will represent the $10 \%$ of the total energy consumed in 2050 due to the increase in EV [2].

However, integrating EV into the electrical power system has several repercussions since their inclusion generates a high impact in the distribution network, by consuming a large amount of electrical energy that can cause undesirable peaks in the demand curve and possible overloads in transformers and primary circuits. Additionally, it can affect the quality of the electrical power by modifying voltage profiles, causing imbalances in the network, and generating harmonics, among others [3].

Therefore, introducing electric vehicles brings new challenges and discussions in relation to the operation and 
planning of electric power distribution systems, which is why issues related to energy quality, study of scenarios, market of electricity, response to demand, demand management, stability of electrical systems, connection of the vehicle to the network and charging stations and battery exchange have been investigated [4].

The investigations related to EV begin in the '70s [5], in which studies on their electrical requirements and the impact they generate on the distribution network and the generating plants are carried out. In 1993, expectations of the sale of energy for the vehicles were inquired, emphasizing in the peaks of the curve demand that they can produce in hours of high demand, arriving at the conclusion that the distribution systems of the time would not be able to withstand EV penetration greater than $20 \%$ [6].

In 1999, the impact of super loaders on the distribution network was studied using the Montecarlo simulation, with the intention of finding the optimal level of penetration to avoid a strong impact of harmonics [7]. Likewise, in [8] an optimal planning of battery exchange stations is looked for, when charging during off-peak hours, increasing the efficiency of the power systems. Additionally, in [9] a comparison of the benefits of the battery change stations with the battery recharging stations is done, concluding that the exchange stations are more suitable to be implemented in the public transport sector.

Regarding the optimal location of battery charging or recharging stations, we find some investigations like [10]-[12], where the search for capacity and location of fast charging stations is sought taking into account the costs it brings to the network operator and the users.

In order to solve the problem of the optimal location of BSS for $\mathrm{EV}$ in distribution systems, this paper proposes a methodology that uses an evolutionary algorithm as a solution technique. To formulate the problem, a mixed whole nonlinear mathematical model is proposed, which minimizes the investment cost of battery exchange stations and the cost of energy losses. The set of restrictions considers the technical and operational aspects of the problem. To verify the proposed methodology, a real distribution system of a Network Operator in Colombia is used.

This paper is organized as follows. A description of the problem and its mathematical formulation are presented in sections II and III, respectively. Section IV describes how the new planning model is solved. Numerical results are presented in section $\mathrm{V}$, and conclusions in section VI.

\section{PROBLEM DesCRIPTION}

Locating battery exchange stations at any point in the network without analyzing the operating conditions of the system, can imply large energy losses (which translates into economic losses) and technical consequences on the network (overloading of elements and inadequate regulation of voltage). To avoid the above, a methodology that allows to locate BSSs is proposed, generating the least amount of possible losses, considering investment costs, operational costs and the transportation network. The model takes into account the following considerations:

- The technical losses in the system are evaluated in one year of operation.

- The cost of construction of charging stations.

- The cost of the land.

- The minimum power to be installed in the system.

- Voltage and current limits.

- Restriction of distance between BSS.

- Minimum number of BSS.

The mathematical model that describes the problem is presented in (1)-(16). The objective function of (1) is composed of two terms: i) the cost of constructing a BSS and ii) the value of energy losses of the distribution system.

$$
\begin{aligned}
\min \mathrm{z}= & \sum_{j \in J}\left(\alpha_{j} * y_{j}\right)+B * T \sum_{m n \in L} i_{m n}^{2} * R_{m n} \\
\text { s.a. } & S_{i}^{G}=S_{i}^{D}+\sum_{\substack{j \in \Omega i \\
i \in N}} V_{j} \cdot i_{i j}^{*}+K u \cdot \mu k_{j} \\
& \\
& S_{n}^{G} \leq S_{m n}^{\max } \quad \forall j \in \Omega_{i}, \forall i \in N \\
& i_{m n} \leq i_{m n}^{\max } \quad \forall j \in \Omega_{N} \quad \forall, n \in L \\
& V_{\min } \leq v_{n} \leq V_{\max } \quad \forall n \in N \\
& K u \cdot \mu k_{j} \leq C \cdot y_{j} \quad \forall j \in J \\
& \sum_{j \in J} y_{j} \geq K \\
& K u \sum_{j \in J} \mu k_{j} \geq F \\
& y_{i}+y_{k} \leq 1 \quad \forall D_{i k} \leq k d, \quad \forall i, k \in J \\
& y_{i}+y_{k} \leq 2 \quad \forall D_{i k} \geq k d, \quad \forall i, k \in J \\
& i_{m n} \in \mathbb{R} \\
& S_{n}^{D} \in \mathbb{R} \\
& S_{n}^{G} \in \mathbb{R} \\
& \mu k_{j} \in\{0,1,2,3\} \\
& v_{n} \in \mathbb{R} \\
& y_{j} \in\{0,1\}
\end{aligned}
$$

In (2) the power balance equation is presented, in which the Kirchhoff Laws and Ohm's law are considered. In (3), (4) and (5) the limits of injected power, the capacity of the network lines and the voltage limits in each node respectively are considered.

In (6) it is guaranteed that the maximum load for each constructed BSS does not exceed its maximum allowed limit. In (7) it is ensured that a minimum number of recharging stations must be built. In (8) it is indicated that the load of all the BSSs is greater than a determined value. In (9) and (10) it is intended that the location of the BSSs be separated by a distance greater than a predefined value. In (11) to (16) the nature of each variable is shown.

\section{Solution Methodology}

To solve the mathematical model described in Section II, a genetic algorithm (GA) is used, which, contrary to heuristic techniques, has mechanisms for escaping optimal local solutions; however, it must be taken into account that these 
types of techniques do not guarantee a global optimum. Despite this, these algorithms have been used to solve various optimization problems, finding high-quality solutions [13].

GA is a search method that follows Charles Darwin's theory of evolution to solve different problems. This process represents the natural selection present in nature, where the best-gifted individuals compete with other individuals with limited resources. To do this, we start from an initial population from which the most outstanding individuals are selected according to the function of adaptation to then reproduce and/or mutate them, and finally obtain a new generation of individuals that will be more suitable than the previous generation.

The algorithm starts with a set of solutions (represented by chromosomes) that is known as the initial population. The solutions of a population are taken and used to form a new population. This is motivated by the fact that the new population will be better than the previous one. The solutions that are selected to form new solutions (offspring) are selected based on the most appropriate according to the adaptation function. This is repeated until a certain condition is fulfilled (for example, the number of generations). The general steps of the GA are as follows:

i. Generate an initial population.

ii. Calculate the objective function of each configuration of the population and store the incumbent (best configuration), with the objective of knowing which of the previous configurations are the most suitable.

iii. Apply a selection operator to choose the individuals that will move on to the next generation.

iv. Perform recombination.

v. Apply mutation and finish generating the new population for the next generation.

vi. Verify the stop criterion. If it has not been met, return to step ii.

Some of the aspects considered are described below. The initial population is generated randomly and has a total of 200 individuals. One selection per tournament is used. Regarding the coding, there are three input vectors: i) the vector of load blocks $\left(\mathrm{uk}_{\mathrm{j}}\right)$, ii) the binary variables $\left(\mathrm{y}_{\mathrm{j}}\right)$ and iii) the possible nodes $(\mathrm{J})$ to install BSS. The vector $\mathrm{uk}_{\mathrm{j}}$ represents the load blocks with an integer codification with a range of [0-3], where 0 means that there is no load, and the numbers 1,2 and 3 are associated with BSS values of $30 \mathrm{~kW}, 60 \mathrm{~kW}$, and 90 $\mathrm{kW}$, respectively.

Figure 1 shows how this problem is coded, where $u k_{j}, y_{j} \mathrm{y}$ $J$ are row vectors that contain the load, the decision binary variable and the candidate nodes respectively. It is important to note that the candidate node in position $\mathrm{x}$ is given the load of $u k_{j}$ in the same position. For example, to node 1 corresponds a load of $3(90 \mathrm{~kW})$ and to node 2 a load of $2(30$ $\mathrm{kW})$. It is observed in the second vector that nodes 6 and 9 have no proposal for the location of BSS.

$$
\begin{aligned}
& \begin{array}{l|l|l|l|l|}
\multicolumn{4}{c}{\text { Load blocks }} \\
u k_{j}=\begin{array}{|l|l|l|l|l|}
\hline 3 & 2 & 0 & 1 & 0 \\
\hline
\end{array}
\end{array} \\
& \text { Binary variable } \\
& y_{j}=\begin{array}{|l|l|l|l|l|}
\hline 1 & 1 & 0 & 1 & 0 \\
\hline
\end{array} \\
& J=\begin{array}{|l|l|l|l|l|}
\multicolumn{4}{c}{\text { Candidate nodes }} \\
\hline 1 & 3 & 6 & 8 & 9 \\
\hline
\end{array}
\end{aligned}
$$

Fig. 1. Codification of the problem

\section{NUMERICAL RESULtS}

To verify the methodology described in Section II, a distribution system of 123 nodes is used, which topology is radial and operates at a voltage level of $13.2 \mathrm{kV}$. The methodology is implemented in Matlab. The database of the test system can be consulted in [14].

To better illustrate the behavior of the methodology, different study cases are presented in the following way. Initially, the location and loading of the BSS are shown, starting with the losses of the distribution system (second term of the objective function). Then the next term of the objective function (construction cost of the BSS) and the constraints described in Section II are added gradually.

The results obtained are shown graphically in Fig. 2 to Fig. 6 , where the distribution system is represented by solid lines, the nodes with an adjacent number are possible points to install BSS, and the nodes with an X represent the location selected by the methodology. A square represents the substation and the nodes are shown with small circles.

Figure 2 shows the results taking into account the second term of the objective function that corresponds to the losses of the distribution system (Case 1). As you can see, there are no nodes selected to install BSS. The results are as expected since the GA seek to minimize the terms corresponding to the objective function, so adding any additional load increases its value.

Due to the above, there is a need to add certain restrictions that make the algorithm locate BSS. Figure 3 shows the results taking into account the second term of the objective function (losses of the network) and a restriction that establishes a minimum amount of demand of $210 \mathrm{~kW}$ (Case 2), which is divided into the nodes 9,14 and 16 , all with a value of $90 \mathrm{~kW}$ (consumption of the BSS) is added.

As can be seen, the selected nodes are the closest to the substation because they only consider the energy losses, generating the value of the objective function be low.

In Fig. 4 the two terms of the objective function that correspond to investment costs in BSS and energy losses (Case 3) are considered. In the same way, the demand is established in $210 \mathrm{~kW}$, which is distributed in nodes 33,44 and 54, all of them with a value of $90 \mathrm{~kW}$. When comparing these results with Case 2 (see Fig. 3), it can be observed how the investment costs in BSS are affected, placing them at a greater distance from the source. 


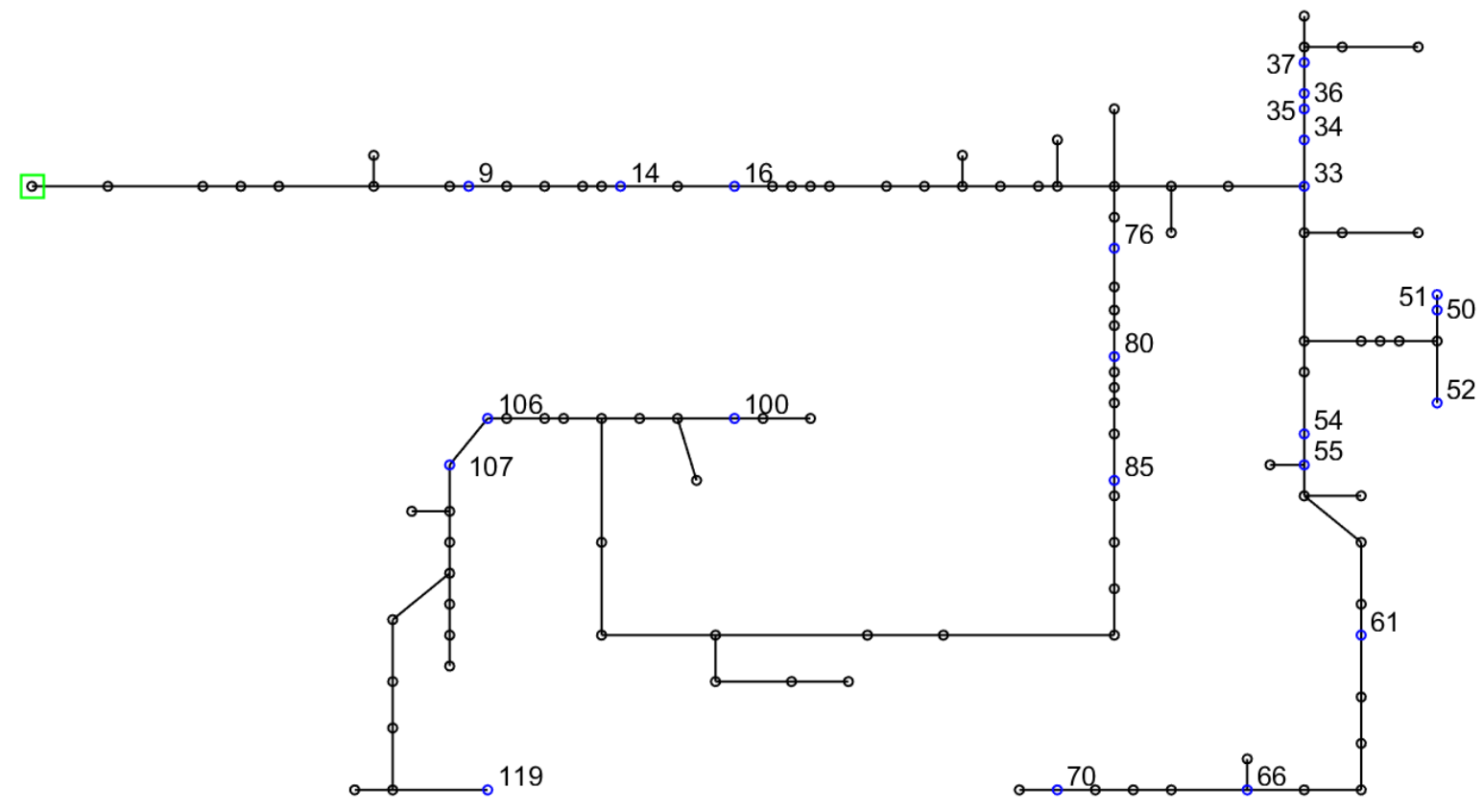

Fig. 2. Location of BSS - Case1

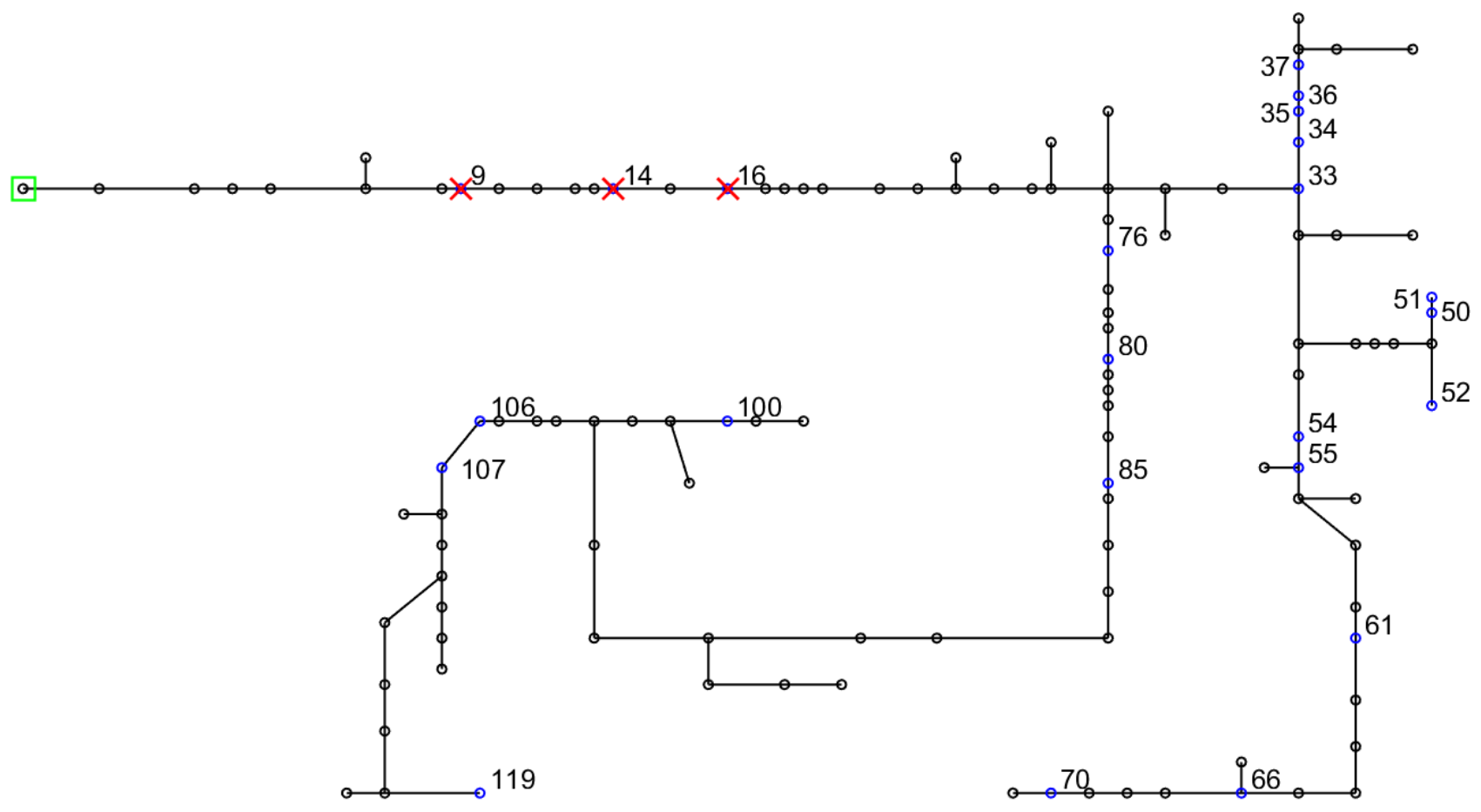

Fig. 3. Location of BSS - Case 2 


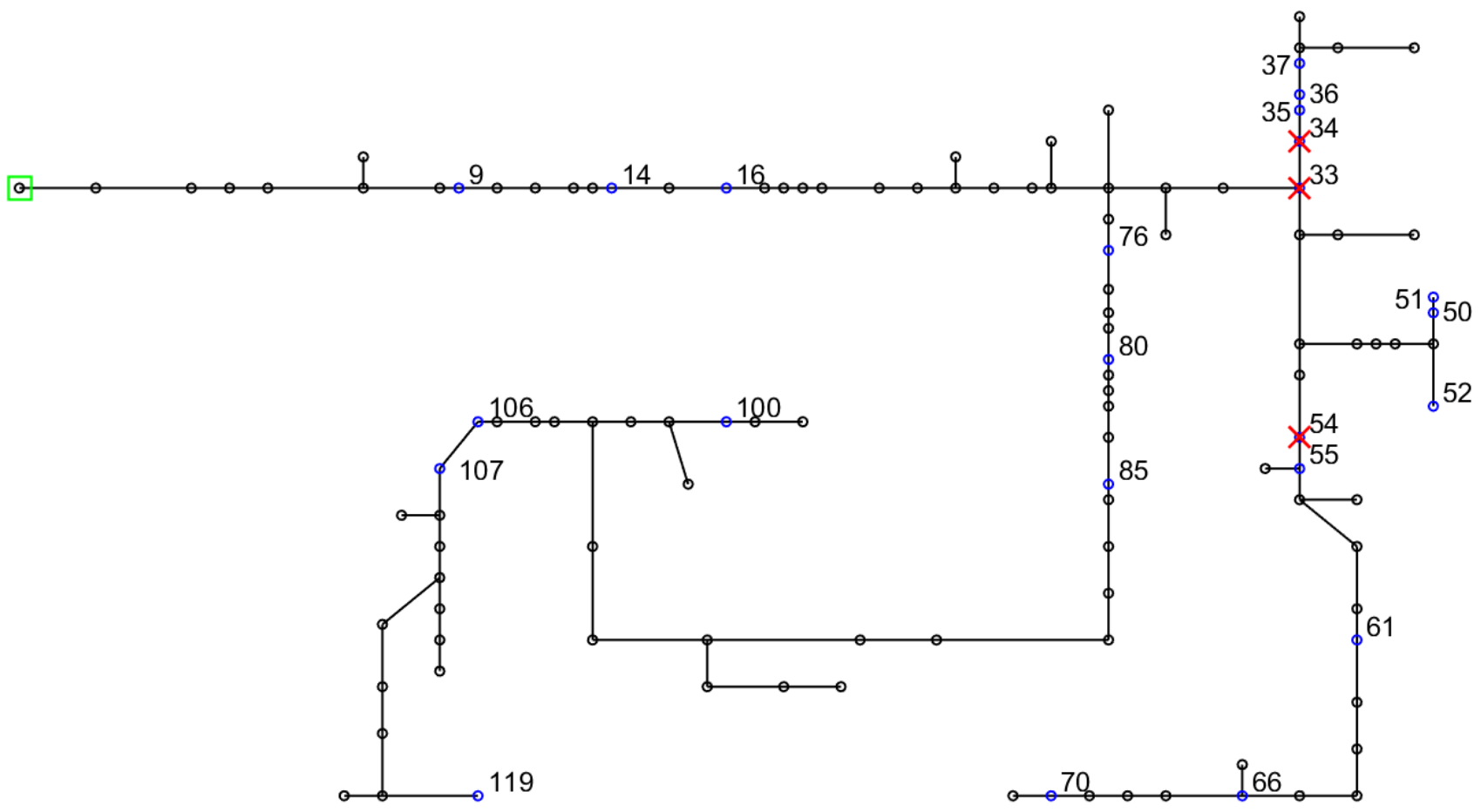

Fig. 4. Location of BSS - Case 3

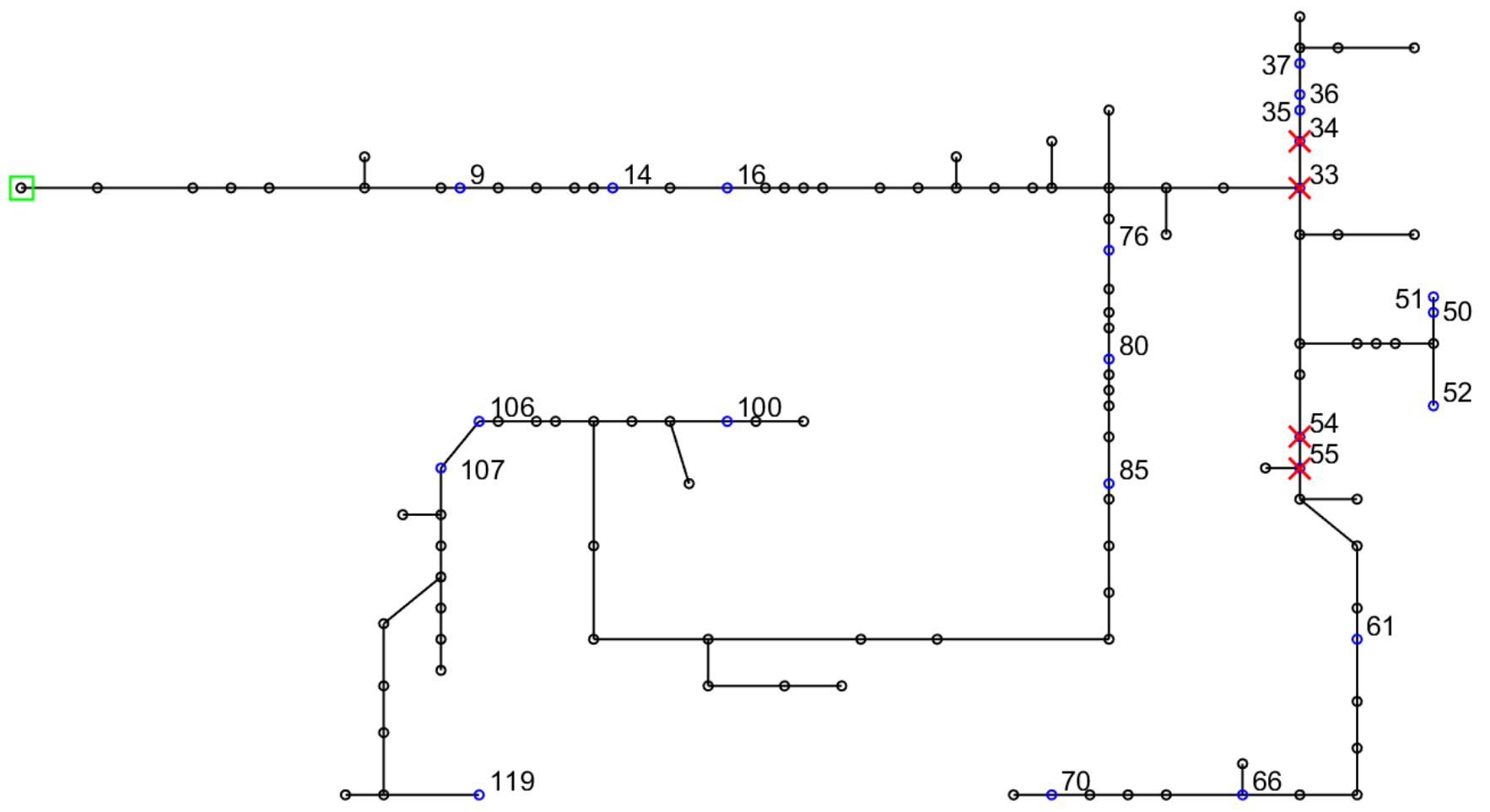

Fig. 5. Location of BSS - Case 4 


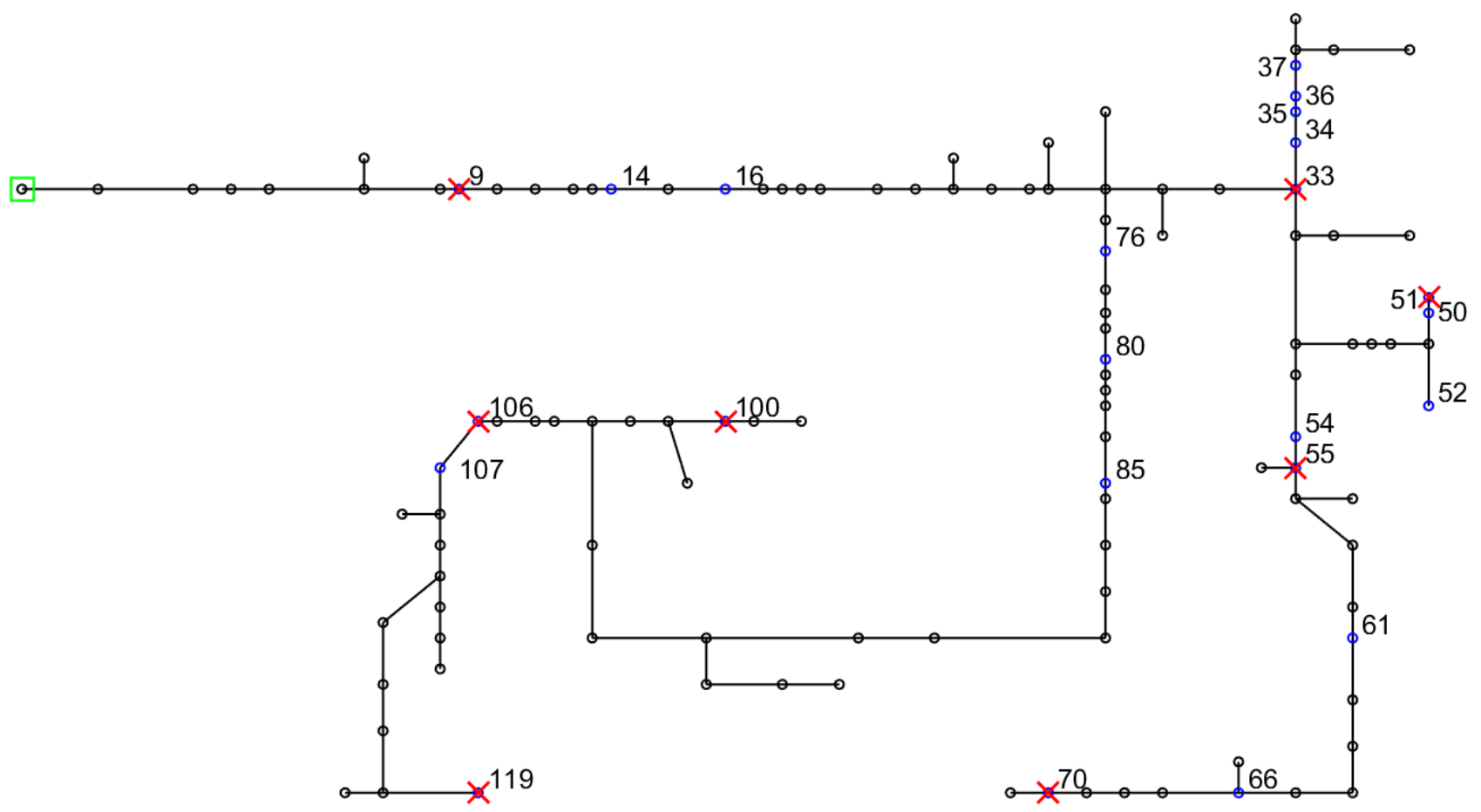

Fig. 6. Location of BSS - Case 5

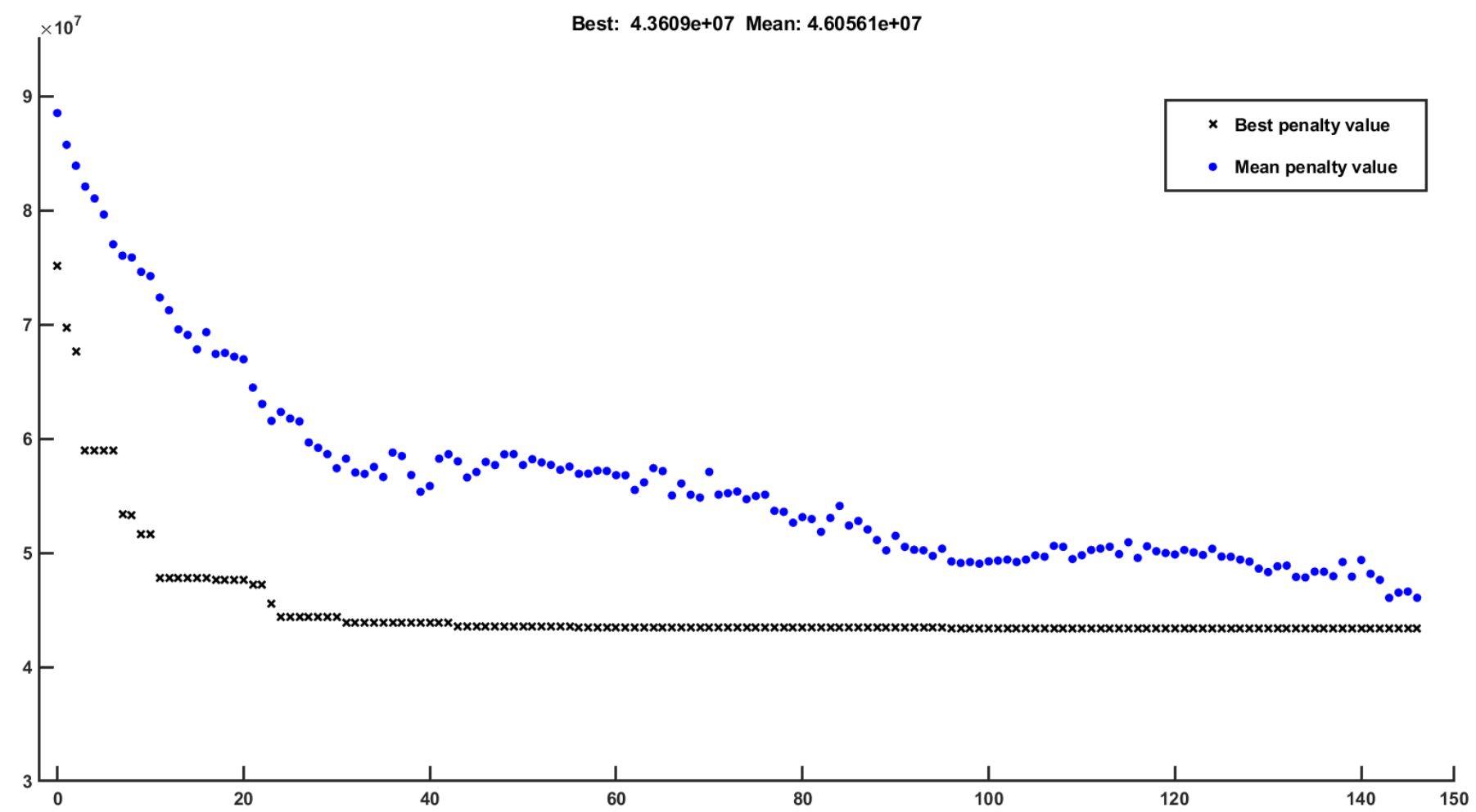

Fig. 7. Evolution of the GA (Generations vs Objective function) 
Case 4 can be observed in Fig. 5, which maintains a minimum load of $210 \mathrm{~kW}$ and the restriction of placing at least 4 BSS is added, distributing the load in nodes 33, 34, 54 and 55 with values of $90 \mathrm{~kW}, 60 \mathrm{~kW}, 30 \mathrm{~kW}$, and $30 \mathrm{~kW}$, respectively. Most of the load is located in the nodes electrically closest to the source and to comply with the minimum amount of BSS, the methodology assigns them the minimum load value to the farthest nodes.

Finally, in case 5 (Fig. 6) the distance restriction is added. This case considers the entire mathematical model presented in (1)-(16). This restriction forces the algorithm to locate the BSSs with spacing between them greater than a specific value. As can be seen in Fig. 6 the chosen nodes are more distributed along the circuit, where the distribution of the load is made for nodes $9(90 \mathrm{~kW}), 33(90 \mathrm{~kW}), 51(90 \mathrm{~kW}), 55(60 \mathrm{~kW}), 70(30$ $\mathrm{kW}), 100(30 \mathrm{~kW}), 106(30 \mathrm{~kW})$ and $119(30 \mathrm{~kW})$. For this case a minimum load of $450 \mathrm{~kW}$ is established, a minimum number of BSS equal to 8 and a spacing between them greater than 300 meters.

Figure 7 shows the behavior of the GA, where on the horizontal axis are the generations used by the algorithm and on the vertical axis the objective function. In this figure you can find two behaviors: i) points that correspond to the average value and ii) $(\mathrm{X})$ that represent the best value of each generation. The first generation is obtained randomly, giving the objective function a high value. For the next generations, you can see how the results of the objective function are better each time, until the best value in the solution space is found. In this case, a stopping criterion of 50 generations was used without improving the incumbent of the problem.

\section{CONCLUSIONS}

Due to the growing demand for electric vehicles, a methodology that optimally locates BSS was proposed, reducing operating costs in electricity distribution networks. For this, a mixed whole nonlinear mathematical model was developed and implemented that allows us to find the location and capacity of BSS for electric vehicles in distribution systems taking into account factors such as costs, distribution of battery exchange stations and operative limits of the distribution network, allowing network operators to have a good quality reference point for the planning and analysis of their networks.

The results show that the genetic algorithm applied to problems of localization and capacity of BSS, offers results of good quality since they manage to minimize the investment and operation costs that entail to include these elements in the distribution system.

\section{REFERENCES}

[1] N.C. Kar, K.L.V. Iyer, A. Labak, X. Lu, C. Lai, A. Balamurali, B. Esteban, M. Sid-Ahmed., "Courting and Sparking: Wooing Consumers? Interest in the EV Market," in IEEE Electrification Magazine, vol. 1, no. 1, pp. 21-31, Sept. 2013. Accessed on: March, 17, 2019, DOI: 10.1109/MELE.2013.2272481.

[2] International Energy Agency, "Technology roadmap Smart Grids". [Online]. Available: http://www.iea.org
[3] K. Clement-Nyns, E. Haesen and J. Driesen, "The Impact of Charging Plug-In Hybrid Electric Vehicles on a Residential Distribution Grid," in IEEE Transactions on Power Systems, vol. 25, no. 1, pp. 371-380, Feb. 2010. Accessed on: March, 17, 2019, DOI: 10.1109/TPWRS.2009.2036481.

[4] A. Arias L., J. D. Sánchez A., L. H. Martínez, R. A. Hincapie and M. Granada, "An IEEE Xplore database literature review regarding the interaction between electric vehicles and power grids," 2015 IEEE PES Innovative Smart Grid Technologies Latin America (ISGT LATAM), Montevideo, 2015, pp. 673-678. Accessed on: March, 18, 2019, DOI: 10.1109/ISGT-LA.2015.7381237.

[5] E. Valsera-Naranjo, A. Sumper, P. Lloret-Gallego, R. Villafafila-Robles y A. Sudria-Andreu, "Electrical vehicles: State of art and issues for their connection to the network," de 2009 10th International Conference on Electrical Power Quality and Utilisation, EPQU'09, 2009. Accessed on: March, 19, 2019, DOI: 10.1109/EPQU.2009.5318813.

[6] J. T. Salihi, "Energy Requirements for Electric Cars and Their Impact on Electric Power Generation and Distribution Systems," in IEEE Transactions on Industry Applications, vol. IA-9, no. 5, pp. 516-532, Sept. 1973. Accessed on: March, 19, 2019, DOI: 10.1109/TIA.1973.349925.

[7] F. Koyanagi, T. Inuzuka, Y. Uriu and R. Yokoyama, "Monte Carlo simulation on the demand impact by quick chargers for electric vehicles," 1999 IEEE Power Engineering Society Summer Meeting. Conference Proceedings (Cat. No.99CH36364), Edmonton, Alta, Canada, 1999, pp. 1031-1036. Accessed on: March, 21, 2019, DOI: 10.1109/PESS.1999.787457.

[8] D. Zheng, F. Wen and J. Huang, "Optimal planning of battery swap stations," International Conference on Sustainable Power Generation and Supply (SUPERGEN 2012), Hangzhou, 2012, pp. 1-7. Accessed on: March, 22, 2019, DOI: 10.1049/cp.2012.1846.

[9] Y. Zheng, Z. Y. Dong, Y. Xu, K. Meng, J. H. Zhao and J. Qiu, "Electric Vehicle Battery Charging/Swap Stations in Distribution Systems: Comparison Study and Optimal Planning," in IEEE Transactions on Power Systems, vol. 29, no. 1, pp. 221-229, Jan. 2014. Accessed on: March, 22, 2019, DOI: 10.1109/TPWRS.2013.2278852, [Online].

[10] A. Rajabi-Ghahnavieh and P. Sadeghi-Barzani, "Optimal Zonal FastCharging Station Placement Considering Urban Traffic Circulation," in IEEE Transactions on Vehicular Technology, vol. 66, no. 1, pp. 45-56, Jan. 2017. Accessed on: March, 22, 2019, DOI: 10.1109/TVT.2016.2555083.

[11] A. Awasthi, D. Chandra, S. Rajasekar, A. K. Singh, A. Raj and K. M. Perumal, "Optimal infrastructure planning of electric vehicle charging stations using hybrid optimization algorithm," 2016 National Power Systems Conference (NPSC), Bhubaneswar, 2016, pp. 1-6. Accessed on: March, 22, 2019, DOI: 10.1109/NPSC.2016.7858941.

[12] S. Chen, Y. Shi, X. Chen and F. Qi, "Optimal location of electric vehicle charging stations using genetic algorithm," 2015 17th Asia-Pacific Network Operations and Management Symposium (APNOMS), Busan, 2015, pp. 372-375. Accessed on: March, 23, 2019, DOI: 10.1109/APNOMS.2015.7275344.

[13] R.A. Gallego, E.M. Toro and A.H. Escobar, "Técnicas Heurísticas y Metaheurísticas," Universidad Tecnológica de Pereira, First Edition, 2015. ISBN: 978-958-722-207-4.

[14] F.A. Osorio, "Ubicación óptima de estaciones de recarga de energía eléctrica para intercambio de baterías para vehículos eléctricos," Eng. Thesis, Dept. Elect. Eng., Technological University of Pereira, Colombia, 2017.

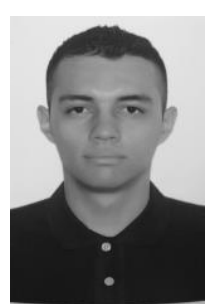

Fabio A. Osorio was born in Pereira, Risaralda, Colombia in 1994. He received his BEE and M.Sc. from the Technological University of Pereira (Universidad Tecnológica de Pereira), Colombia, in 2017. He is currently pursuing a master's degree in the Department of Electrical Engineering at the Technological University of Pereira. His research interests include power system optimization and power system planning.

ORCID:_https://orcid.org/0000-0002-5950-1948 


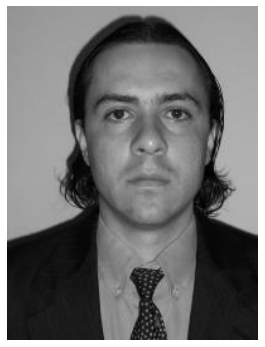

Ricardo A. Hincapié was born in Pereira, Risaralda, Colombia in 1976. He received his BEE, M.Sc and Ph.D. degrees in Electrical Engineering from the Technological University of Pereira, Colombia, in 2001, 2004 and 2017 respectively. He is currently professor in the Department of Electrical Engineering at the Technological University of Pereira (Universidad Tecnológica de Pereira), Colombia. His research interests include power system distribution planning and applied optimization to power systems.

ORCID: https://orcid.org/0000-0001-8282-7826

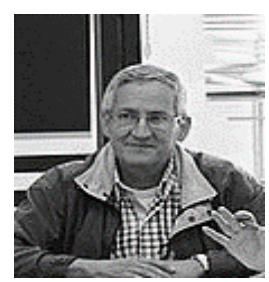

Ramón A. Gallego was born in Circasia, Quindío, Colombia in 1957. He received the B.Sc. degree in electrical engineering from the Universidad Tecnológica de Pereira (UTP), Pereira, Colombia, in 1981 and the M.Sc. degree in electrical engineering from the Universidad Nacional, Bogotá, Colombia in 1985. He is specialist in energetic planning from the Universidad de los Andes, Bogotá, Colombia. In 1997 he received the Ph.D. degree in engineering from Universidade Estadual de Campinas, Sao Paulo, Brasil. His research interests include power system transmission and distribution planning and applied optimization to energy systems. Currently, he is professor of the Electrical Engineering Program at the Universidad Tecnológica de Pereira.

ORCID: https://orcid.org/0000-0002-0160-8929 